\title{
Lymphocyte reconstitution after DMF discontinuation in clinical trial and real-world patients with MS
}

Andrew Chan, MD, PhD, John Rose, MD, Enrique Alvarez, MD, PhD, Amit Bar-Or, MD, Helmut Butzkueven, MBBS, PhD, Robert J. Fox, MD, Ralf Gold, MD, PhD, Mark Gudesblatt, MD, Jodi Haartsen, MS, NP, Tim Spelman, MBS, BSc, Katy Wright, MPAS, PA-C, Diana Ferraro, MD, PhD, Patrizia Sola, MD, PhD, Suzanne Hodgkinson, PhD, Tomas Kalincik, MD, PhD, Jeannette Lechner-Scott, MD, PhD, Christopher McGuigan, MD, Karen Spach, PhD, Chongshu Chen, PhD, Sami Fam, PhD, Fan Wu, PhD, and Catherine Miller, PharmD, MPH

Neurology: Clinical Practice December 2020 vol. 10 no. 6 510-519 doi:10.1212/CPJ.0000000000000800
Correspondence

Catherine Miller

catherine.miller@biogen.com

\begin{abstract}
\section{Background}

Delayed-release dimethyl fumarate (DMF) has demonstrated robust efficacy in treating patients with relapsing-remitting multiple sclerosis. Decreases in absolute lymphocyte count (ALC) are a wellknown pharmacodynamic effect of DMF treatment, but lymphocyte recovery dynamics are not well characterized after discontinuation of DMF.
\end{abstract}

\section{Methods}

Data sources included the Biogen DMF integrated clinical trial data set, a retrospective US chart abstraction study, and data from MSBase. We assessed rate and time course of lymphocyte reconstitution after DMF discontinuation.

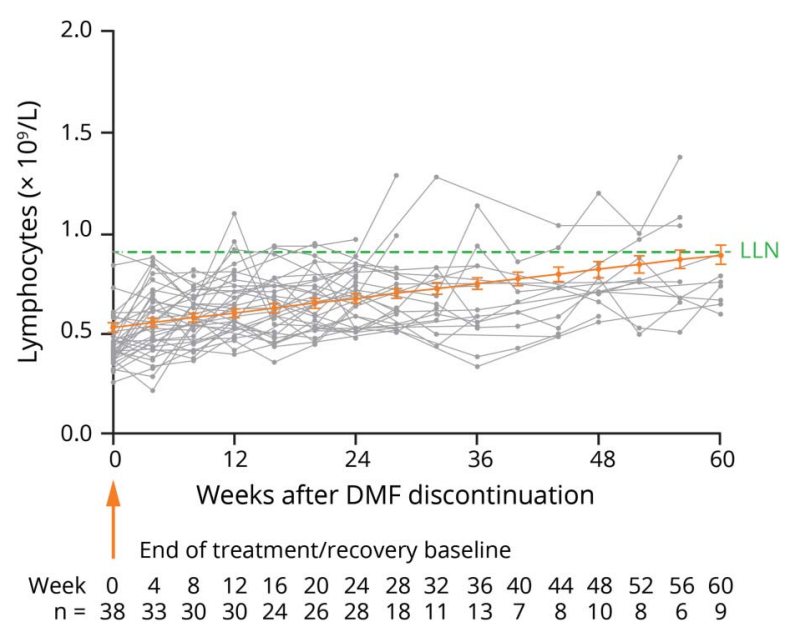

\section{Results}

The majority of patients who developed lymphopenia while treated with DMF and subsequently discontinued treatment experienced ALC reconstitution. The median time to reach ALC $\geq 0.8 \times 10^{9} / \mathrm{L}$ was $2-4$ months after discontinuation for patients treated in real-world data sets; the median time to reach ALC $\geq 0.91 \times 10^{9} / \mathrm{L}$ was 2 months after discontinuation in DMF clinical trials. Severity of lymphopenia on treatment and decline in ALC within the first 6 months did not affect the ALC reconstitution rate after DMF discontinuation; rather, ontreatment lymphopenia duration influenced the reconstitution rate. In patients with severe, prolonged lymphopenia for $\geq 3$ years, lymphocyte reconstitution to $\geq 0.91 \times 10^{9} / \mathrm{L}$ was $12-18$ months vs $2-3$ months in patients with lymphopenia persisting $<6$ months.

Department of Neurology (AC), Inselspital, Bern University Hospital, University of Bern, Switzerland; Division of Neuroimmunology and Neurovirology (JR), University of Utah, Salt Lake City, UT; Brain Institute (JR), University of Utah, Salt Lake City, UT; Department of Neurology (JR), University of Utah, Salt Lake City, UT; Rocky Mountain Multiple Sclerosis Center at the University of Colorado (EA), Aurora, CO; Department of Neurology and Center for Neuroinflammation and Experimental Therapeutics (AB-O), Perelman School of Medicine, University of Pennsylvania, Philadelphia, PA; Children's Hospital of Philadelphia (AB-O), Perelman School of Medicine, University of Pennsylvania, Philadelphia, PA; Central Clinical School (HB), Monash University, VIC, Australia; Mellen Center for Multiple Sclerosis Treatment and Research (RJF), Cleveland Clinic, OH; Department of Neurology (RG), St. JosefHospital, Ruhr University Bochum, Germany; South Shore Neurologic Association PC (MG), Patchogue, NY; Eastern Health MS Service (JH), Box Hill, VIC, Australia; Department of Medicine and Melbourne Brain Centre at the Royal Melbourne Hospital (TS), University of Melbourne, Parkville, VIC, Australia; Department of Neurology and Neurotherapeutics (KW), University of Texas Southwestern Medical Center, Multiple Sclerosis and Neuroimmunology Imaging Program, Clinical Center for Multiple Sclerosis, Dallas, TX; Department of Neuroscience (DF, PS), Neurology Unit, Azienda Ospedaliera Universitaria, Modena, Italy; Liverpool Hospital (SH), NSW, Australia; Department of Medicine (TK), CORe Unit, University of Melbourne, VIC, Australia; Department of Neurology (TK), Royal Melbourne Hospital, VIC, Australia; School of Medicine and Public Health (JL-S), University Newcastle, NSW, Australia; Department of Neurology (UL-S), John Hunter Hospital, Hunter New England Health, Newcastle, NSW, Australia; Department of Neurology (C. McGuigan), St. Vincent's University Hospital and University College, Dublin, Ireland; Envision Pharma Group (KS), Fairfield, CT; and Biogen (CC, SF, FW, C. Miller), Cambridge, MA.

Funding information and disclosures are provided at the end of the article. Full disclosure form information provided by the authors is available with the full text of this article at Neurology.org/cp.

The Article Processing Charge was funded by Biogen.

This is an open access article distributed under the terms of the Creative Commons Attribution-NonCommercial-NoDerivatives License 4.0 (CC BY-NC-ND), which permits downloading and sharing the work provided it is properly cited. The work cannot be changed in any way or used commercially without permission from the journal. 


\section{Conclusions}

The majority of patients who discontinued DMF due to lymphopenia experienced ALC reconstitution within 2-4 months following DMF discontinuation. This may help guide clinicians in managing patients who develop lymphopenia during DMF treatment. Prolonged lymphopenia on DMF treatment is associated with slow lymphocyte recovery after DMF discontinuation.

Delayed-release dimethyl fumarate (DMF) is an effective treatment in patients with relapsing forms of multiple sclerosis (MS), ${ }^{1-4}$ with a well-characterized safety profile. ${ }^{5,6}$ Decreasedlymphocyte counts are a pharmacodynamic effect of DMF. ${ }^{7}$ In the first year of treatment in pivotal phase 3 trials (DEFINE/ CONFIRM), absolute lymphocyte counts (ALCs) declined $\sim 30 \%$ and then stabilized, ${ }^{7}$ regardless of baseline ALC. ${ }^{8}$ ALCs remained above lower limit of normal (LLN; $\left.0.91 \times 10^{9} / \mathrm{L}\right)$ for $76 \%$ of patients in the first year of treatment. ${ }^{9}$ Few (2\%) DMFtreated patients experienced severe, prolonged lymphopenia (ALC $<0.5 \times 10^{9} / \mathrm{L}$ for $\geq 6$ months). ${ }^{7}$ As of August 312019 , there were $>425,000$ patients treated with DMF worldwide, representing $>810,000$ patient-years of exposure; to date, the rate of progressive multifocal leukoencephalopathy (PML) with DMF-treatment was estimated as $<1 / 100,000$ patient-years. The majority of cases of PML occurred in the setting of moderate $\left(<0.8 \times 10^{9} / \mathrm{L}\right)$ or severe, prolonged lymphopenia. ${ }^{10,11}$ To minimize potential risks of prolonged moderate-to-severe lymphopenia, DMF labels recommend monitoring lymphocyte counts every 6-12 months after DMF initiation and considering DMF discontinuation for patients with severe, prolonged lymphopenia. In an integrated clinical trial analysis, including patients followed for up to 11 years, aside from 1 case of PML, there was no increased incidence of malignancy, or opportunistic or serious infection, regardless of on-treatment ALC or T-cell subset count. $^{12-14}$

Limited data are available describing lymphocyte dynamics in patients who develop lymphopenia and subsequently discontinue DMF. Using clinical trial and real-world data, we assessed the lymphocyte reconstitution rate and time course after DMF discontinuation and time to initiating sequential therapy for patients with lymphopenia who discontinued DMF.

\section{Methods}

In patients with relapsing-remitting MS treated with DMF who developed lymphopenia and subsequently discontinued DMF, lymphocyte reconstitution was assessed using 3 distinct data sources: (1) an integrated analysis of DMF clinical trials, and real-world patient data collected via phase 4 retrospective chart abstraction study from (2) five US centers and (3) the MSBase registry.

MSBase is an international, online registry designed to collect prospective data on patients with MS. Participating neurologists contribute data on diagnosis, treatment, and progress, thereby facilitating collaborative research through investigator-initiated substudies. To date, 22 neurologists from 11 countries have contributed data from 2,400 patients. The MSBase sites are separate from the relevant US centers included in the chart abstraction study. ${ }^{15}$

\section{Integrated analysis of DMF clinical trials}

The integrated analysis of DMF clinical trials (DMF integrated clinical trials) comprised a phase $2 \mathrm{~b}$ study (NCT00168701), the phase 3 DEFINE (NCT00420212), and CONFIRM (NCT00451451) studies, and the ENDORSE (NCT00835770) extension study, including data as of 01 September 2017 ( $n=2,513$ patients). Blood collection (including ALC) while on treatment occurred at least every 12 weeks. ALC grades according to the Common Terminology Criteria for Adverse Events v4.0 were as follows: grade $0\left(\geq \mathrm{LLN}, \geq 0.91 \times 10^{9} / \mathrm{L}\right)$; grade $1(<\mathrm{LLN}$ to $\geq 0.8 \times$ $\left.10^{9} / \mathrm{L}\right)$; grade $2\left(<0.8\right.$ to $\left.\geq 0.5 \times 10^{9} / \mathrm{L}\right)$; grade $3(<0.5$ to $\left.\geq 0.2 \times 10^{9} / \mathrm{L}\right)$; and grade $4\left(<0.2 \times 10^{9} / \mathrm{L}\right)$.

For patients with ALC < LLN at DMF discontinuation, ALCs were collected at least every 12 weeks, until ALC returned to LLN $\left(\right.$ ALC $\left.<0.91 \times 10^{9} / \mathrm{L}\right)$ or the patient discontinued the study. Patients with an ALC < LLN at DMF discontinuation and $\geq 1$ post-DMF ALC value or who temporarily discontinued DMF but did not experience severe, prolonged lymphopenia were included in lymphocyte reconstitution analyses $(\mathrm{N}=$ 138). Patients with severe, prolonged lymphopenia $(<0.5 \times$ $10^{9} / \mathrm{L}$ for $\geq 6$ months) were analyzed separately due to the prolonged duration of on-treatment lymphopenia $(\mathrm{N}=38)$. The product label recommendation to consider treatment interruption in patients with severe, prolonged lymphopenia was added to the protocol after the study had been ongoing $\sim 7$ years. Therefore, this cohort is not considered representative of current real-world DMF use because some clinical trial patients experienced lymphopenia for longer than would be expected with current recommendations. ${ }^{10}$

For the reconstitution analysis, patients were stratified by the following: (1) lowest ALC recorded on DMF treatment or ALC at discontinuation: $<0.5 \times 10^{9} / \mathrm{L}, \geq 0.5$ to $<0.8 \times 10^{9} / \mathrm{L}$, and $\geq 0.8$ to $<0.91(\mathrm{LLN}) \times 10^{9} / \mathrm{L}$; (2) median ALC at discontinuation: $\leq$ median $\left(0.73 \times 10^{9} / \mathrm{L}\right)$ and $>$ median $(0.73 \times$ $\left.10^{9} / \mathrm{L}\right)$; and (3) ALC in the first 6 months of DMF treatment: any ALC $<0.8 \times 10^{9} / \mathrm{L}$ and always $\geq 0.8 \times 10^{9} / \mathrm{L}$.

\section{MSBase/US chart review}

This phase 4 retrospective chart abstraction study included retrospective medical record review data (April 2017-March 2018) from 5 US centers and MSBase registry data as of November 17,2017 . The primary end point was the ALC change 


\section{Limited data are available} describing lymphocyte dynamics in patients who develop lymphopenia and subsequently discontinue DMF.

over time. Key inclusion criteria included treatment with DMF for 3-24 months, as per standard of care, and DMF discontinuation for any reason; baseline ALC $>\operatorname{LLN}\left(0.91 \times 10^{9} / \mathrm{L}\right)$; $\geq 2$ ALC assessments of $<$ LLN during DMF treatment; and $\geq 2$ ALC assessments after DMF treatment, $\geq 1$ recorded $\geq 90$ days after DMF discontinuation. Included patients had ALC $<$ LLN at discontinuation. Patients treated with $\mathrm{DMF}$ for $\geq 2$ years were excluded to obtain patients whose exposure to DMF was less than that of the integrated clinical trials.

\section{Statistical methods}

For the DMF integrated clinical trials, a linear mixed-effect model with random intercept and random slope of time (in weeks) was used to assess slope of ALC reconstitution after DMF discontinuation, adjusted for age and ALC group at discontinuation, and an interaction between time and ALC group. Estimated overall slope is based on a linear mixedeffect model, adjusted only for age.

For MSBase and US chart review, slopes of ALC reconstitution in the first 12 weeks after DMF discontinuation were calculated using a linear mixed-effect model of ALC measures with random intercept and random slope of time, in weeks, adjusted for age and ALC group at discontinuation $\left(<0.5 \times 10^{9} / \mathrm{L}\right.$ or $\geq 0.5 \times$ $\left.10^{9} / \mathrm{L}\right)$ as well as interaction between time and ALC group.

\section{Standard protocol approvals, registrations, and patient consents}

For the DMF integrated clinical trials, the studies were approved by central and local ethics committees and conducted in accordance with International Conference on Harmonization Guidelines for Good Clinical Practice and the Declaration of Helsinki. ${ }^{2-4,6}$ All patients provided written informed consent. For the MSBase/US chart review, the local institutional review board at each institution approved these studies.

\section{Data availability}

Anonymized data can be shared at the request of qualified investigators for purposes of replicating procedures and results.

\section{Results}

In the DMF integrated clinical trials, as of September 1, 2017, the lymphocyte analysis population consisted of 2,470 patients $(10,971$ patient-years of follow-up) with $\geq 1$ postbaseline ALC recorded. The DMF integrated clinical trials of patients with ALC $<$ LLN at DMF discontinuation and $\geq 1$
post-DMF ALC value-excluding patients with severe, prolonged lymphopenia - represent 5.5\% (138/2513) of the overall analysis population (table). Of the 138 patients, the DMF treatment duration was the median (range) of 35.6 (3-117) months; follow-up ranged from 0.1 to 34.3 months for the entire population.

The primary reason for treatment discontinuation was adverse events ( $30 \%$ of patients, $n=42$ ); of these patients, the majority discontinued due to low lymphocyte counts or white blood cell counts $(26 \%, \mathrm{n}=11)$ or tolerability events, including GI or flushing and flushing-related events $(26 \%, \mathrm{n}=11)$. The mean (SD) baseline ALC was $1.7(0.5) \times 10^{9} / \mathrm{L}$. The median (range) minimum ALC on DMF treatment was $0.6(0.2-0.9) \times 10^{9} / \mathrm{L}$, representing a $63 \%$ median reduction from baseline. The median time to onset of lymphopenia (first ALC $<0.91 \times 10^{9} / \mathrm{L}$ ) was 6.2 months after DMF initiation. At discontinuation, the median (range) ALC was $0.73(0.29-0.90) \times 10^{9} / \mathrm{L}$. After DMF discontinuation, the median time (range) of follow-up was $1.25(0.10-34.3)$ months.

In the MSBase and US chart review analysis, data from 74 patients (184 patient-years) were evaluated, and 33 patients met the inclusion criteria (US centers, 27; MSBase, 6); the median (range) age was $52(20-75)$ years; the median (range) baseline ALC was $1.6(1.0-3.9) \times 10^{9} / \mathrm{L}$ (table). Patients were treated with DMF for a median (range) of 17.8 (4.8-23.9) months; the primary reason for discontinuation was lymphopenia (61\% of patients who discontinued). The median (range) minimum ALC on DMF treatment was 0.5 $(0.2-0.8) \times 10^{9} / \mathrm{L}$, representing a $71 \%$ median reduction from baseline. The median time to onset of lymphopenia (first ALC $<0.91 \times 10^{9} / \mathrm{L}$ ) was 5.3 months after DMF initiation. The median (range) ALC was $0.5(0.2-1.0) \times 10^{9} / \mathrm{L}$ at discontinuation. After DMF discontinuation, the median (range) follow-up period was 10.1 (3.3-31.8) months.

\section{ALC after discontinuation}

In the DMF integrated clinical trials, 138 patients had mild or moderate lymphopenia at any time while on DMF. From DMF discontinuation and thereafter, nearly all patients $(99 \%$ $[137 / 138])$ maintained an ALC of $\geq 0.5 \times 10^{9} / \mathrm{L}$, and $62 \%$ $(86 / 138)$ reached an $A L C \geq \operatorname{LLN}\left(\geq 0.91 \times 10^{9} / \mathrm{L}\right)$ in the recovery period (figure $1 \mathrm{~A}$ ). Of the 52 patients who did not reach LLN, 39 discontinued the study and were lost to follow-up before reaching this milestone. After DMF discontinuation, ALC levels were restored to LLN within 2 months, on average. Of the 86 patients who had ALC $<0.91$ at DMF discontinuation and reached an ALC of LLN, the median time to reach ALC $\geq 0.91 \times 10^{9} / \mathrm{L}$ was 7 weeks, based on Kaplan-Meier estimates. The median time to reach an ALC of $\geq 0.8 \times 10^{9} / \mathrm{L}$ was 6 weeks for patients who had ALC $<0.8 \times 10^{9} / \mathrm{L}$ at DMF discontinuation.

In MSBase and US chart review, the first median (range) ALC measurement $>3$ months (10.1 [3.3-31.8] months of follow-up) after DMF discontinuation was $0.8(0.1-2.2) \times 10^{9} / \mathrm{L}$. Nearly all 
Table Baseline characteristics of patients who discontinued DMF in the MSBase and US chart review and DMF integrated clinical trials

\begin{tabular}{|c|c|c|}
\hline Baseline characteristic & DMF integrated clinical trials $(n=138)$ & MSBase and US chart review $(n=33)$ \\
\hline Female, n (\%) & $103(75)$ & $28(85)$ \\
\hline Age at initiation, mean (SD), y & $40(8)$ & $51(12)$ \\
\hline$<50$ & $122(88)$ & $14(42)$ \\
\hline$\geq 50$ & $16(12)$ & $19(58)$ \\
\hline $\begin{array}{l}\text { Baseline ALC, mean (SD) or median } \\
\text { (range), } \times 10^{9} / \mathrm{L}\end{array}$ & $1.7(0.5)$ & $1.6(1.0-3.9)$ \\
\hline $\begin{array}{l}\text { Relapse in } 12 \text { months before DMF } \\
\text { initiation, mean (SD) }\end{array}$ & $0.1(0.3)$ & $0.4(0.8)$ \\
\hline \multicolumn{3}{|l|}{ Previous DMT history, ${ }^{a} \mathrm{n}(\%)$} \\
\hline Interferon & $58(42)$ & $23(72)$ \\
\hline Glatiramer acetate & $12(9)$ & $12(38)$ \\
\hline Natalizumab & $2(1)$ & $8(25)$ \\
\hline Fingolimod & - & $2(6)$ \\
\hline Teriflunomide & - & $2(6)$ \\
\hline Treatment naive & - & $5(16)$ \\
\hline DMF duration, median (range), mo & $45(3-117)$ & $18(5-24)$ \\
\hline Discontinued DMF, $n(\%)^{b}$ & $138(100)$ & $33(100)$ \\
\hline $\begin{array}{l}\text { Follow-up duration after DMF } \\
\text { discontinuation, median (range), mo }\end{array}$ & $0.25(0.10-34.3)$ & $10.1(3.3-31.8)$ \\
\hline
\end{tabular}

Abbreviations: $\mathrm{ALC}=$ absolute lymphocyte count; DMF = dimethyl fumarate; DMT = disease-modifying therapy; MS = multiple sclerosis.

a All known previous DMTs were collected; hence, patients could have multiple responses; for MSBase and US chart review, data were only available for 32 patients.

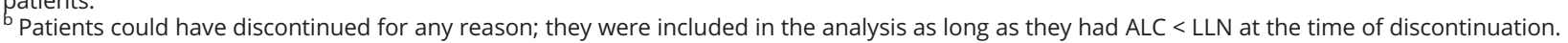

patients $(97 \%[31 / 32])$ reached an ALC of $\geq 0.5 \times 10^{9} / \mathrm{L}$ after DMF discontinuation, and 53\% (17/32) reached an ALC $\geq$ LLN (figure 1B). Of the 15 patients who did not recover to LLN after DMF discontinuation, 4 switched to other diseasemodifying therapies (DMTs) that could have affected their recovery ( 2 fingolimod and 2 rituximab). The 11 patients who did not switch to DMTs known to markedly deplete lymphocytes reached a median (range) $0.83 \times 10^{9} / \mathrm{L}(0.4-0.9)$ during the follow-up period and no longer had ALCs recorded. Four patients were untreated during this period; 3 treated with teriflunomide, 3 with an interferon, and 1 with an undefined DMT. Of patients with $\geq 1$ ALC $<0.8 \times 10^{9} / \mathrm{L}$ on treatment $(\mathrm{n}=32)$, the majority $(78 \%, 25 / 32)$ had $\geq 1$ post-treatment ALC $\geq 0.8 \times$ $10^{9} / \mathrm{L}$. Based on Kaplan-Meier estimates, the median time from DMF discontinuation to reach ALC $\geq 0.8 \times 10^{9} / \mathrm{L}(\mathrm{n}=25 / 32)$ was 17 weeks. The median time to reach an ALC of $\geq 0.91 \times 10^{9} / \mathrm{L}$ ( $\mathrm{n}=18 / 32$ ) was 46 weeks (11.5 months) for patients who had ALC $<0.8 \times 10^{9} / \mathrm{L}$ on DMF treatment.

\section{Predictors of recovery after DMF discontinuation}

On-treatment lymphopenia severity was not associated with the rate of post-DMF ALC reconstitution, but did influence the time to restore ALC to LLN. For the DMF integrated clinical trials, the recovery rate was similar regardless of ALC at discontinuation (slope 0.035 for $>$ median ALC $[0.73 \times$ $\left.10^{9} / \mathrm{L}\right]$ vs 0.043 for $\leq$ median ALC at discontinuation; $p=$ 0.504; figure $1 \mathrm{C}$ ). Given the similar rates of recovery, patients who discontinued with higher ALCs reached LLN sooner. For patients in the DMF integrated clinical trials who discontinued $\leq$ median $\left(0.73 \times 10^{9} / \mathrm{L}\right)$, time to ALC $>0.91 \times 10^{9} / \mathrm{L}$ was 6.9 weeks compared with 1.5 weeks for patients who discontinued $>$ median based on the model. The estimate of overall slope, excluding patients with prolonged lymphopenia, was mean (standard error) 0.039 (0.006), adjusted only for age; this is comparable to the estimates of slope by the ALC subgroup (0.043 and 0.035).

Similarly, in the MSBase and US chart review, ALC levels increased after DMF discontinuation at a similar rate for $0-12$ weeks, regardless of whether the last ALC while on treatment was $<$ or $\geq 0.5 \times 10^{9} / \mathrm{L}$ (median ALC at discontinuation; slope 0.046 vs 0.032 ; $p=0.405$; figure $1 \mathrm{D}$ ).

Early drops in ALC have been associated with higher incidence of developing severe, prolonged lymphopenia 
Figure 1 Proportion of patients with lymphocyte reconstitution based on ALC at DMF discontinuation in (A) DMF integrated clinical trials and (B) MSBase and US chart review patients; and lymphocyte recovery after DMF discontinuation for 0-12 weeks by linear mixed-effect model for (C) DMF integrated clinical trials in patients $\leq$ or $>$ median ALC at discontinuation and (D) MSBase and US chart review in patients $\leq$ or $>0.5 \times 10^{9} / \mathrm{L} \mathrm{ALC} \mathrm{at}$ discontinuation for 12 weeks

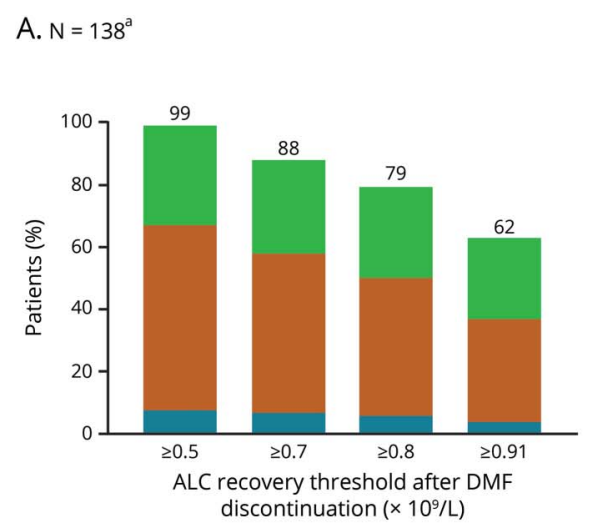

C

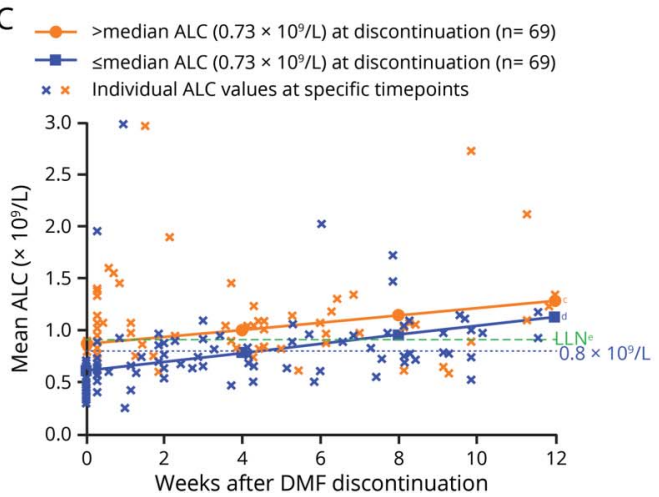

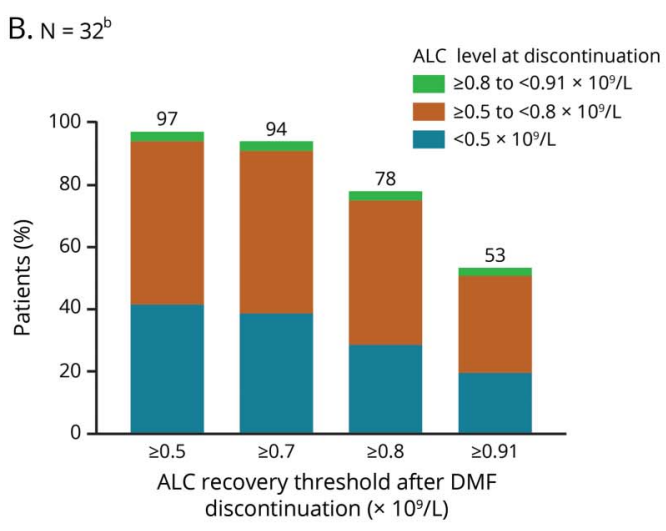

D

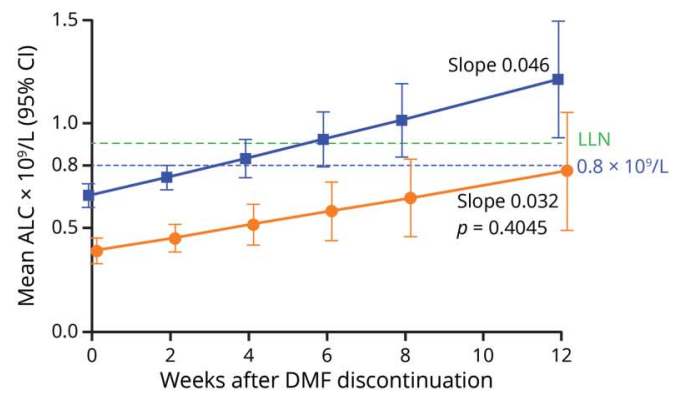

a One patient did not recover to $\geq 0.5 \times 10^{9} / \mathrm{L}$ during the follow-up period. ${ }^{\mathrm{b}}$ One patient did not recover to $\geq 0.5 \times 10^{9} / \mathrm{L}$ during a follow-up period of 287 days. The follow-up period for the 1 patient that did not recover to LLN is 8 days after DMF discontinuation. ${ }^{~}$ Estimated slope $0.043 \times 10^{9} / \mathrm{L} / \mathrm{wk}$. ${ }^{\mathrm{d}}$ Estimated slope $0.035 \times$ $10^{9} / \mathrm{L} / \mathrm{wk}, p=0.504$. $0.91 \times 10^{9} / \mathrm{L}$. (A and B) Patients with ALC $<0.91 \times 10^{9} / \mathrm{L}$ at DMF discontinuation and $\geq 1$ post-DMF ALC value were included. Patients with $<0.5 \times 10^{9} / \mathrm{L}$ for $\geq 6$ months were excluded. The number of patients who achieved an ALC threshold of $\geq 0.7 \times 10^{9} / \mathrm{L}$ is included in the number of patients who achieved an ALC threshold of $\geq 0.5 \times 10^{9} / \mathrm{L}$. The median (range) follow-up period for recovery after DMF discontinuation for the entire sample $(\mathrm{N}=33$ ) was 10.1 (3.3-31.8) months. (C) In a linear mixed-effect model to assess slope of post-DMF ALC reconstitution, groups were determined by the last ALC recorded at or before discontinuation. Patients with ALC $<0.91 \times 10^{9} / L$ at DMF discontinuation and $\geq 1$ post-DMF ALC value were included $(N=138 ; n=69$ per group). Patients with an ALC $<0.5 \times 10^{9} / \mathrm{L}$ for $\geq 6$ months were excluded. The median ALC at discontinuation was $0.73 \times 10^{9} / \mathrm{L}$. (D) The estimated ALC reconstitution rate after discontinuing DMF based on repeated measures models for 0-12 weeks (with measures restricted to the first 3 months only). Patient estimates were grouped by the last ALC on DMF (assumed to be measured on day 1 after discontinuation); for last $A L C$ on DMF $\geq 0.5 \times 10^{9} / L, n=19 ;$ for last $A L C$ on $D M F<0.5 \times 10^{9} / L, n=$ 14. The mixed-effect models were adjusted for time since DMF discontinuation, age at discontinuation, last on-DMF ALC groups, and interaction between time and ALC groups. Estimates at each time point were based on the fitted model with Cls given using Kenward-Roger approximation. $p$ value is for the difference in the slope estimates from the model. ALC = absolute lymphocyte count; DMF = dimethyl fumarate; MS = multiple sclerosis; LLN = lower limit of normal.

while on treatment ${ }^{7}$; therefore, lymphocyte recovery after DMF discontinuation was assessed by ALC levels in the first 6 months of treatment to understand if there is also an association with reconstitution. No such association was observed (figure 2). Mean ALCs reached LLN after 8 weeks of discontinuation regardless of whether ALC levels were $<$ or $\geq 0.8 \times 10^{9} / \mathrm{L}$ within the first 6 months of DMF treatment, although the sample size is relatively small.

\section{Lymphocyte recovery and clinical outcomes in patients with severe, prolonged lymphopenia}

Duration of lymphopenia was associated with a prolonged time to reconstitution in the 38 patients with severe, prolonged lymphopenia (figure 3). Patients with ALC $<0.5 \times 10^{9} / \mathrm{L}$ for $\geq 6$ months were exposed to DMF for $\sim 6$ (median) years before discontinuation. The majority, $31 / 38$ ( $82 \%)$ of this small subgroup, had ALC levels $<0.5$ $\times 10^{9} / \mathrm{L}$ persisting for $\geq 6$ months by 3 years on DMF treatment, yet treatment continued for a median of 2.9 years after ALC levels reached $<0.5 \times 10^{9} / \mathrm{L}$ DMF discontinuation. While patients in the severe, prolonged lymphopenia group achieved an ALC of $\geq 0.8 \times 10^{9} / \mathrm{L}$ $(50 \%[19 / 38])$ or $0.91 \times 10^{9} / \mathrm{L}(29 \%[11 / 38])$ during the follow-up period, the median time to reach $0.8 \times 10^{9} / \mathrm{L}$ was 35 weeks. Importantly, in patients followed for up to 11 years, severe, prolonged lymphopenia on treatment $(\mathrm{n}=53)$ was not associated with increased incidence of malignancy ( 0.007 vs 0.004$)$, serious herpes zoster ( 0 vs $0.0004)$, serious infection ( 0.017 vs 0.010$)$, or opportunistic infection (0.003 vs 0 ) compared with ALC $\geq$ LLN $(\mathrm{n}=1475)$. 
Lymphocyte counts reconstituted to normal levels within 8-16 weeks if patients did not have prolonged
lymphopenia beyond 6 months.

Although the sample size is small $(\mathrm{n}=38)$, the majority of patients (71\%) did not have a relapse during the 6 months following discontinuation. For context, the unadjusted annualized relapse rate (ARR) during the first 6 months after discontinuing DMF (0.362) was generally consistent with that of an untreated patient population; the 6-month adjusted ARR on placebo in DEFINE/CONFIRM was 0.430. There was insufficient follow-up time to assess the other groups.

\section{Other DMTs after DMF discontinuation}

Using data from MSBase and US chart review ( $\mathrm{n}=$ 33), lymphocyte reconstitution was not significantly affected when alternative DMTs with no known effect on lymphocyte profiles were initiated after DMF discontinuation (figure 4, A and $\mathrm{B}$ ). Other DMTs were generally initiated a median (range) of 5 (0-50) weeks after DMF discontinuation, corresponding to median ALC $>\sim 0.8 \times 10^{9} / \mathrm{L}$. Teriflunomide, rituximab, glatiramer acetate, and interferons were the most common alternative DMTs initially started after DMF discontinuation (figure 4C). No patients reinitiated DMF after discontinuation. The samples sizes were

Figure 2 DMF integrated clinical trials: lymphocyte recovery after DMF discontinuation based on ALC decreases in the first 6 months of treatment

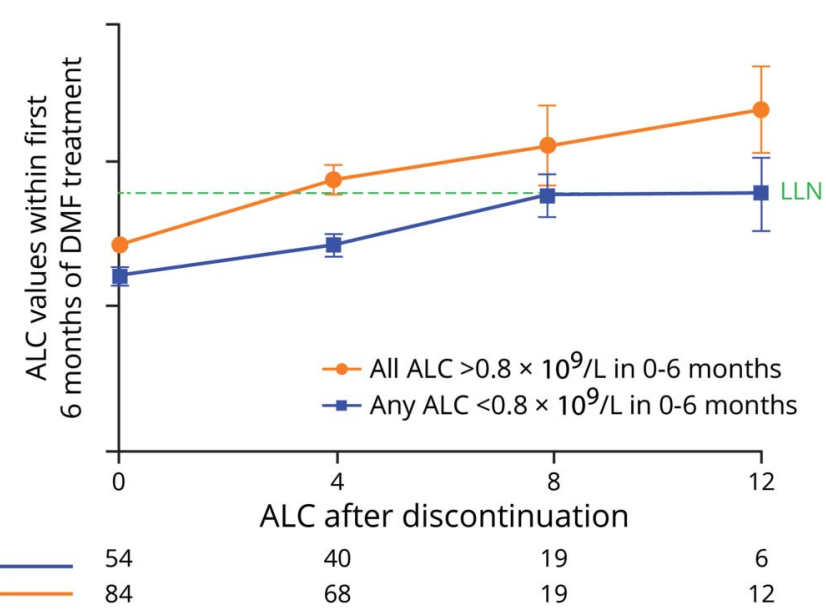

The mean (standard error) ALC is shown. Patients with ALC $<0.91 \times 10^{9} / \mathrm{L}$ at DMF discontinuation and $\geq 1$ post-DMF ALC value were included $(N=138)$. $\mathrm{ALC}=$ absolute lymphocyte count; DMF = dimethyl fumarate; $\mathrm{LLN}=$ lower limit of normal.
Figure 3 Individual patient ALC values in patients with severe, prolonged lymphopenia from the DMF integrated clinical trials

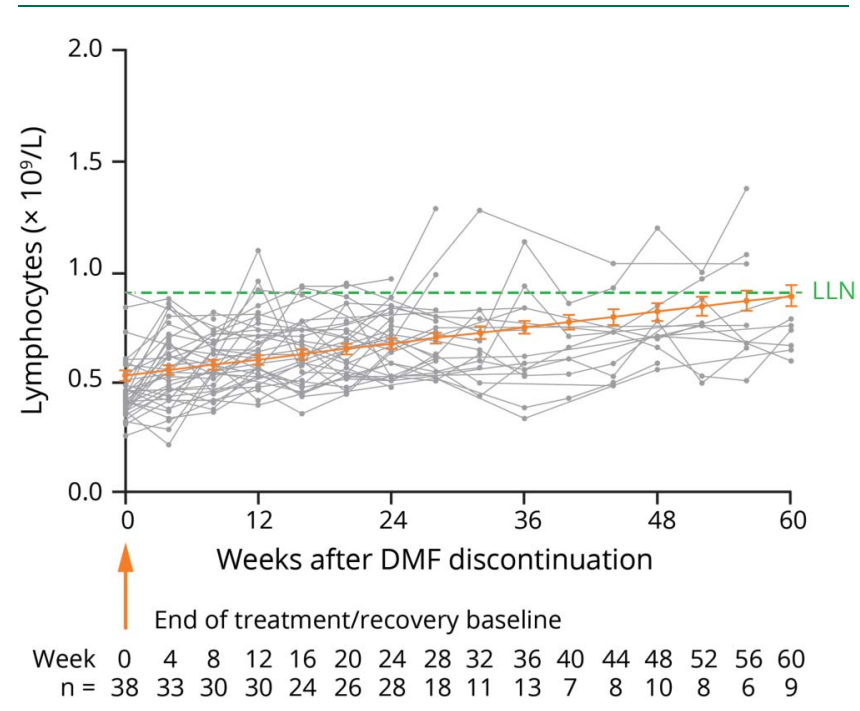

The mean (standard error) ALC is shown. Patients with ALC $<0.91 \times 10^{9} / \mathrm{L}$ at DMF discontinuation and $\geq 1$ post-DMF ALC value were included. Individual patient ALC values are shown in gray. The estimated linear mean line over time (shown in orange) was calculated using a linear mixed-effect model. The severe, prolonged lymphopenia group $(n=38)$ was defined as patients with ALCs $<0.5 \times 10^{9} / \mathrm{L}$ for $\geq 6$ months and $\geq 2$ post-DMF ALC values. Patients were permitted to receive alternate DMTs after discontinuation. ALC $=$ absolute lymphocyte count; DMF = dimethyl fumarate; $\mathrm{DMT}$ = disease-modifying therapy.

too small to compare reconstitution rates by alternative DMTs.

\section{Discussion}

Lymphocyte counts reconstituted to normal levels within 8-16 weeks if patients did not have prolonged lymphopenia beyond 6 months. Therefore, time to ALC recovery will be longer for patients with severe rather than mild lymphopenia at discontinuation, confirming previous smaller studies. ${ }^{16,17}$ On average, ALC reconstitution is linear for the first 8 weeks after DMF discontinuation, and then the recovery rate slows (figures 2 and 4A). Lymphocyte reconstitution is influenced by duration of severe lymphopenia on DMF, as suggested by the 38 patients with severe, prolonged lymphopenia who recovered to $\geq \mathrm{LLN}$ in $\sim 12-18$ months. The data suggest that the lymphocyte reconstitution rate is not affected by DMF treatment duration, lymphopenia severity, or early drops in ALC. These results complement the findings previously reported by Mehta et al. ${ }^{8}$ While both analyses use the same source database, data presented herein are a subset of the population, which aligns with the real-world data set.

There are several limitations to consider. The sample size was small for both data sets, particularly for patients treated in the real-world setting. Unfortunately, lymphocyte counts are not part of the minimum data set in MSBase, and the vast 
Figure 4 MSBase and US chart review: (A and B) Posttreatment lymphocyte reconstitution for patients after discontinuing treatment with DMF through starting another DMT and (C) post-DMF DMTs
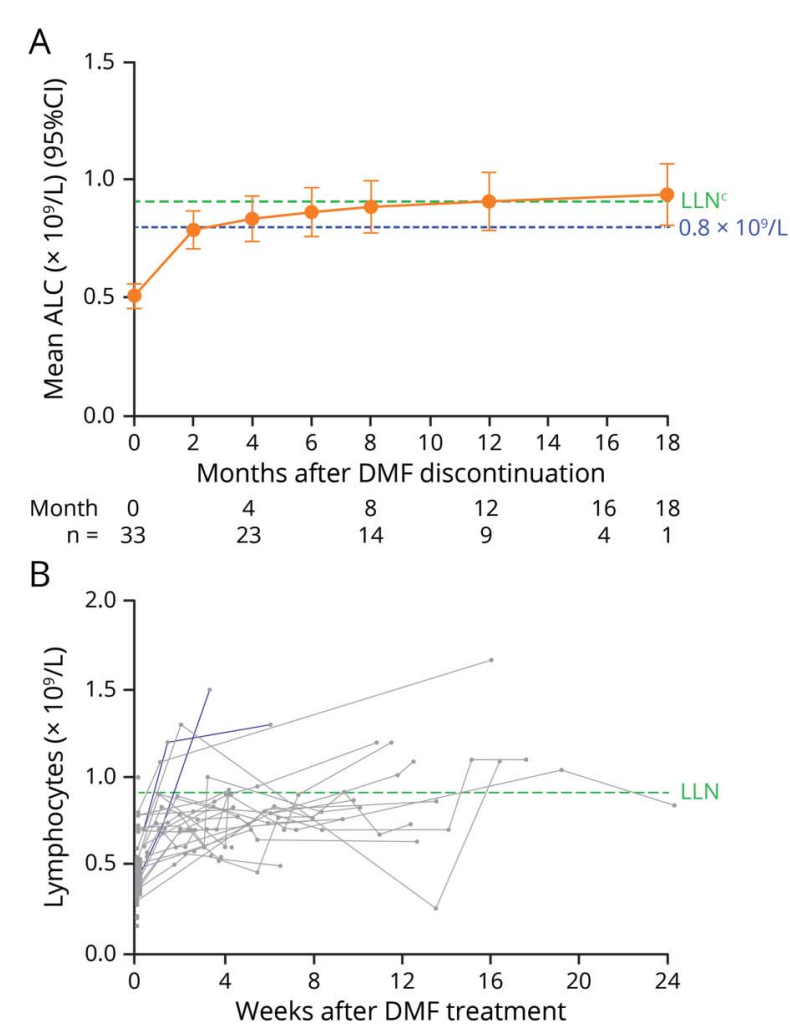

C

\begin{tabular}{|c|c|c|}
\hline $\begin{array}{c}\text { Post-DMF } \\
\text { DMTa }^{a}\end{array}$ & $\begin{array}{c}\text { Overall, } \mathrm{n}(\%) \\
(\mathrm{N}=33)\end{array}$ & $\begin{array}{c}\text { Weeks to start another DMT } \\
\text { after DMF discontinuation, } \\
\text { median (range) }\end{array}$ \\
\hline Teriflunomide & $6(18)$ & $21(11-47)$ \\
\hline Rituximab & $5(15)$ & $03(0.1-3)$ \\
\hline Glatiramer acetate & $4(12)$ & $9.2(1-33)$ \\
\hline Interferon & $4(12)$ & $5(0-26)$ \\
\hline Fingolimod & $2(6)$ & $3(2-4)$ \\
\hline Natalizumab & $2(6)$ & $3(1-5)$ \\
\hline Ocrelizumab & $1(3)$ & 50 \\
\hline Other & $2(6)$ & $2(0-4)$ \\
\hline None & $6(18)$ & - \\
\hline Not reported & $1(3)$ & - \\
\hline
\end{tabular}

For patients who switched to fingolimod, natalizumab, rituximab, or ocrelizumab after DMF discontinuation, only the ALC observations taken

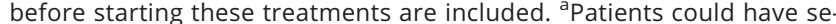
quentially switched to >1 DMT; only the patient's first alternative DMT after DMF discontinuation is shown. No patients reinstated DMF after discontinuation. (A) The mixed-effect model regresses absolute ALC measure on log2-transformed time (days) since discontinuation of DMF with random intercept and slope, adjusted for age at discontinuation, ALC group at discontinuation $\left(<0.5 \times 10^{9} / \mathrm{L}\right.$ or $\left.\geq 0.5 \times 10^{9} / \mathrm{L}\right)$, and the interaction between the log2-transformed time and ALC group. The last ALC on DMF is assumed to be measured on day 1 after discontinuation. A month is assumed to be 30 days. The estimates at each time point are based on the fitted model with standard errors and Cls given using Kenward-Roger approximation. (B) ALC measures are shown for individual patients, and each patient's line ends when the patient begins an alternate therapy. $\mathrm{ALC}=$ absolute lymphocyte count; $\mathrm{DMF}=$ dimethyl fumarate; DMT = disease-modifying therapy; $L L N=$ lower limit of normal. majority of DMF-treated patients do not have lymphocyte count data available, thereby making the data sets ineligible for analysis. However, some centers systematically track lymphocyte counts, either spontaneously or as part of an Australian MSBase substudy called MSFirst. In addition, in the real-world setting, lymphocyte counts are not collected systematically, further limiting the number of patients with data available at specific time points in a retrospective analysis. Because reconstitution may be apparent earlier in patients with more frequent assessments and lymphocyte reconstitution assessments are influenced by visit schedule, data collected from patients with sporadic visits may over- or underestimate the time to reconstitution. Furthermore, a selection bias influencing which lymphocyte recovery data are available is possible. Together with the short duration of follow-up after DMF discontinuation for patients in the clinical trials, this data set has only a limited number of patients with data available over time. However, these data, albeit sparse, may be useful for clinicians and patients when considering treatment discontinuation and/or a treatment switch from DMF.

In addition, the analysis of post-treatment DMTs is limited to a select few centers in Australia and the European Union and likely not a true reflection of post-DMF treatment dynamics worldwide. Because of strict inclusion criteria, the trials do not represent the full spectrum of patients who are exposed to DMF in routine care. This may also contribute to some discrepancy between the data sets.

However, despite the collection differences in real-world data compared with structured clinical trial data, the reconstitution rate was similar for both groups. As similar inclusion and exclusion criteria were applied and consistent analysis methods used, these data sets can serve as confirmatory to each other, increasing the confidence that these data accurately represent the true ALC recovery rate after DMF discontinuation.

In the analysis of patients treated in the real-world setting, inclusion of patients from the retrospective chart review was limited to patients treated with DMF for $\leq 2$ years, because patients treated for a longer period were well represented in the DMF integrated clinical trial. However, in very rare instances, delayed lymphopenia has been noted to occur after 2 years of therapy. ${ }^{18}$

These data on the dynamics of lymphocyte reconstitution are important for clinicians when managing patients who develop lymphopenia during DMF treatment. ALC monitoring is an effective tool for recognizing patients who are at risk of prolonged moderate to severe lymphopenia. ${ }^{7,18}$ Management of DMF-treated patients involves considerations of when to discontinue treatment and also when and to which alternate therapy to transition. These considerations can be informed by understanding (1) the established pattern 
of lymphocyte decline during DMF treatment, (2) the effects of DMF treatment in patients who exhibit ALC decline, (3) the risk of DMF treatment in patients who exhibit ALC decline, and (4) the dynamics of ALC reconstitution after treatment discontinuation.

Although this analysis has provided some understanding of those factors, the question remains if we can predict the ability of lymphocyte counts to return to normal levels, as there is variability in time of reconstitution when reviewing individual patient-level data. For the overall population in this analysis, the degree, magnitude, and speed of ALC decline did not influence reconstitution in patients with severe lymphopenia for $<6$ months on treatment. Thus, clinicians should diligently monitor ALC and consider discontinuation at the recommended time if patients have severe, prolonged lymphopenia. Therefore, these data demonstrate that the use of DMF per label recommendations generally allows for lymphocyte recovery within 2-4 months, similar to data observed in a smaller study. ${ }^{16}$

Of the patients with severe, prolonged lymphopenia in this analysis, there were no differences in rates of serious or opportunistic infections, and the majority did not have a relapse in the 6 months after DMF discontinuation. There is no washout recommended between stopping DMF (per country-specific guidelines) and starting an alternate DMT. In this data set, clinicians tended to restart an alternate DMT $\sim 5$ weeks after DMF discontinuation, which coincided with ALC $\sim 0.8 \times 10^{9} / \mathrm{L}$. It is unclear whether time, ALC value, or another variable was the driving factor for these decisions. Albeit small, this data set suggests that the ARR after DMF discontinuation is similar to that of an untreated patient population.

The majority of patients experienced ALC reconstitution within 2-4 months of DMF discontinuation. Reconstitution rate was not significantly affected by severity of lymphopenia, including a lower ALC at discontinuation or early drops in ALC. Patients with longer periods and greater extent of lymphopenia experienced longer times to reconstitution. These data will inform clinicians assessing the benefit-risk when managing patients who develop severe lymphopenia while on DMF and in developing a personalized sequencing strategy for patients with lymphopenia who discontinue DMF. Clinicians can use the information on the ALC recovery rate after discontinuation to consider next steps in DMT treatment.

\section{Acknowledgment}

The authors thank the patients for their participation in this study and the following individuals who contributed to this research: Franco Granella, Julie Prévost, Daniele LA Spitaleri, Ik Lin Tan, Ka-Ho Wong, and Steve Vucic.

\section{Study funding}

This study was sponsored by Biogen (Cambridge, MA). Writing and editorial support for the preparation of this manuscript was provided by Excel Scientific Solutions (Fairfield, CT): funding was provided by Biogen.

\section{TAKE-HOME POINTS}

$\rightarrow$ In an analysis of patients from clinical trials and realworld clinical care, the majority of patients who discontinued DMF due to lymphopenia experienced ALC reconstitution within 2-4 months following DMF discontinuation.

$\rightarrow$ Prolonged lymphopenia on DMF treatment is associated with slower lymphocyte reconstitution after DMF discontinuation.

$\rightarrow$ These results may help guide clinicians in managing patients who develop lymphopenia during DMF treatment.

\section{Disclosure}

A. Chan: compensation for activities with Actelion, Almirall, Bayer, Biogen, Celgene, Genzyme, Merck, Novartis, SanofiAventis, and Teva, all for university research funds, and research support from Biogen, Genzyme, and UCB. J. Rose: research funding from Biogen, Guthy-Jackson Foundation, NIH, National Multiple Sclerosis Society, Teva, and Western Institute for Biomedical Research. E. Alvarez: consulting fees from Actelion, Biogen, Celgene, Genentech, Genzyme, Novartis, and TG Pharmaceuticals and research funding from Biogen, Genentech, Novartis, and Rocky Mountain MS Center. A. Bar-Or: speaker/consulting fees/grant support from Atara, Biogen, Celgene/Receptos, Genentech/Roche, GlaxoSmithKline, MedImmune, Merck/EMD Serono, Novartis, and Sanofi Genzyme. H. Butzkueven: steering committee/advisory board/consulting fees from Biogen, Merck, Novartis, Oxford PharmaGenesis, Roche, and Teva, and research support from Biogen, Merck, National Health and Medical Research Council of Australia, Novartis, MS Research Australia, and UK MS Trust. R.J. Fox has received personal consulting fees from Actelion, Biogen, Celgene, EMD Serono, Genentech, Immunic, Novartis, and Teva; has served on advisory committees for Actelion, Biogen, Immunic, and Novartis; and received clinical trial contract and research grant funding from Biogen and Novartis. R. Gold: honoraria/ research support from Bayer, Biogen, Merck Serono, Novartis, and Teva and compensation from Sage for serving as editor of Therapeutic Advances in Neurological Disorders. M. Gudesblatt: principal investigator for studies sponsored by Acorda, Adamas, Biogen, Novartis, Roche, Sanofi Genzyme, and Teva; speaker bureaus for Biogen, EMD Serono, Novartis, Sanofi Genzyme, and Teva; and consultant for Biogen, EMD Serono, Novartis, and Sanofi Genzyme. J. Haartsen: honoraria for travel, consultation, and speaking from Biogen, Merck, Novartis, Roche, and Sanofi Genzyme. T. Spelman: consulting/advisory board fees and funding for travel from Biogen and speaker honoraria from Novartis. K. Wright: consulting and advisory board fees from Biogen and 
Genzyme. D. Ferraro: scientific advisory boards for Biogen, Merck Serono, and Roche and travel grants and/or speaking honoraria from Biogen, Merck, Novartis, Roche, Sanofi Genzyme, and Teva. P. Sola: scientific advisory boards for Biogen and Teva and funding for travel and speaker honoraria from Biogen, Merck Serono, Novartis, Sanofi Genzyme, and Teva. S. Hodgkinson: honoraria, sponsorship, travel support, and research support from Bayer, Biogen, Merck Serono, Novartis, and Teva. T. Kalincik: scientific advisory boards for Biogen, Merck, Novartis, Roche, and Sanofi Genzyme; steering committee for Brain Atrophy Initiative by Sanofi Genzyme; conference travel support and/or speaker honoraria from BioCSL, Biogen, Merck, Novartis, Sanofi Genzyme, Teva, and WebMD Global; and research support from Biogen. J. Lechner-Scott: travel compensation from Biogen, Merck, and Novartis and honoraria to her institution for talks and advisory board commitments and research grants from Biogen, Merck, Novartis, Roche, and Teva. C. McGuigan: honoraria for consultancy work and/or research funding from Actelion, Biogen, Merck, Novartis, Roche, Sanofi Genzyme, and Teva. K. Spach: employee of and holds stock/stock options in Envision Pharma Group. C. Chen, F. Wu, and C. Miller: employees of and hold stock/stock options in Biogen. S. Fam: former employee of and holds stock/stock options in Biogen. Full disclosure form information provided by the authors is available with the full text of this article at Neurology.org/cp.

\section{Publication history}

Received by Neurology: Clinical Practice July 15, 2019. Accepted in final form October 22, 2019.

Appendix Authors

\begin{tabular}{lll}
\hline Name & Location & Contribution \\
\hline $\begin{array}{l}\text { Andrew Chan, PhD, } \\
\text { MD }\end{array}$ & $\begin{array}{l}\text { University of Bern, } \\
\text { Switzerland }\end{array}$ & $\begin{array}{l}\text { Role in the acquisition of } \\
\text { data; interpreted the data; } \\
\text { and revised the } \\
\text { manuscript for intellectual } \\
\text { content }\end{array}$ \\
& &
\end{tabular}

John Rose, MD University of Utah, Salt Role in the acquisition of
Lake City, UT data; interpreted the data; and revised the manuscript for intellectual content

\begin{tabular}{lll}
\hline $\begin{array}{l}\text { Enrique Alvarez, } \\
\text { MD, PhD }\end{array}$ & $\begin{array}{l}\text { Rocky Mountain } \\
\text { Multiple Sclerosis } \\
\text { Center at the } \\
\text { University of Colorado, } \\
\text { Aurora, CO }\end{array}$ & $\begin{array}{l}\text { Role in the acquisition of } \\
\text { data; interpreted the data; } \\
\text { and revised the } \\
\text { manuscript for intellectual } \\
\text { content }\end{array}$ \\
\hline Amit Bar-Or, MD & $\begin{array}{l}\text { University of } \\
\text { Pennsylvania, } \\
\text { Philadelphia, PA }\end{array}$ & $\begin{array}{l}\text { Role in the acquisition of } \\
\text { data; interpreted the data; } \\
\text { and revised the } \\
\text { manuscript for intellectual } \\
\text { content }\end{array}$ \\
\hline $\begin{array}{l}\text { Helmut } \\
\text { Butzkueven, MBBS, } \\
\text { PhD }\end{array}$ & $\begin{array}{l}\text { Monash University, } \\
\text { VIC, Australia }\end{array}$ & $\begin{array}{l}\text { Role in the acquisition of } \\
\text { data; interpreted the data; } \\
\text { and revised the } \\
\text { manuscript for intellectual } \\
\text { content }\end{array}$ \\
\hline
\end{tabular}

Appendix (continued)

\begin{tabular}{lll}
\hline Name & Location & Contribution \\
\hline Robert J. Fox, MD & Cleveland Clinic, OH & $\begin{array}{l}\text { Role in the acquisition of } \\
\text { data; interpreted the data; } \\
\text { and revised the } \\
\text { manuscript for intellectual } \\
\text { content }\end{array}$ \\
\hline
\end{tabular}

Ralf Gold, MD, PhD St. Josef-Hospital, Ruhr Role in the acquisition of University Bochum, data; interpreted the data; Germany and revised the manuscript for intellectual content

\begin{tabular}{ll}
\hline Mark Gudesblatt, & South Shore \\
MD & Neurologic Association \\
& PC, Patchogue, NY
\end{tabular}

Role in the acquisition of data; interpreted the data; and revised the manuscript for intellectual content

\begin{tabular}{lll}
\hline Jodi Haartsen, MS, & $\begin{array}{l}\text { Eastern Health MS } \\
\text { NP }\end{array}$ & $\begin{array}{l}\text { Role in the acquisition } \\
\text { Australia }\end{array}$ \\
& & $\begin{array}{l}\text { of data; interpreted } \\
\text { the data; and } \\
\text { revised the manuscript } \\
\text { for intellectual } \\
\text { content }\end{array}$ \\
\end{tabular}

\begin{tabular}{ll}
\hline Tim Spelman, MBS, & University of \\
BSc & Melbourne, Parkville, \\
& VIC, Australia
\end{tabular}

Role in the acquisition of data; interpreted the data; and revised the manuscript for intellectual content

\begin{tabular}{lll}
\hline Katy Wright, MPAS, & University of Texas & Role in the acquisition of \\
PA-C & Southwestern Medical & data; interpreted the data; \\
Center, Dallas, TX & $\begin{array}{l}\text { and revised the } \\
\text { manuscript for intellectual } \\
\text { content }\end{array}$
\end{tabular}

Diana Ferraro, MD, Azienda Ospedaliera Role in the acquisition of PhD Universitaria, Modena, data; interpreted the data; Italy and revised the

manuscript for intellectual content

\begin{tabular}{lll}
\hline $\begin{array}{l}\text { Patrizia Sola, MD, } \\
\text { PhD }\end{array}$ & $\begin{array}{l}\text { Azienda Ospedaliera } \\
\text { Universitaria, Modena, } \\
\text { Italy }\end{array}$ & $\begin{array}{l}\text { Role in the acquisition of } \\
\text { data; interpreted the data; } \\
\text { and revised the } \\
\text { manuscript for intellectual } \\
\text { content }\end{array}$ \\
\hline $\begin{array}{l}\text { Suzanne } \\
\text { Hodgkinson, PhD }\end{array}$ & $\begin{array}{l}\text { Liverpool Hospital, } \\
\text { NSW, Australia }\end{array}$ & $\begin{array}{l}\text { Role in the acquisition of } \\
\text { data; interpreted the data; } \\
\text { and revised the } \\
\text { manuscript for intellectual } \\
\text { content }\end{array}$ \\
\hline
\end{tabular}

Tomas Kalincik, MD, University of Role in the acquisition of

PhD $\quad$ Melbourne; Royal data; interpreted the data; Melbourne Hospital, and revised the

VIC, Australia manuscript for intellectual content

\begin{tabular}{lll}
\hline Jeannette Lechner- & University Newcastle, & Role in the acquisition of \\
Scott, MD, PhD & John Hunter Hospital, & data; interpreted the data; \\
& Newcastle, NSW, & $\begin{array}{l}\text { and revised the } \\
\text { manuscript for intellectual } \\
\text { content }\end{array}$ \\
& Australia &
\end{tabular}

Christopher St Vincent's University Role in the acquisition of

McGuigan, MD Hospital and University data; interpreted the data; College Dublin, Dublin, and revised the Ireland manuscript for intellectual content

\begin{tabular}{lll}
\hline Karen Spach, PhD & $\begin{array}{l}\text { Envision Pharma } \\
\text { Group, Fairfield, CT }\end{array}$ & $\begin{array}{l}\text { Drafted the manuscript } \\
\text { for intellectual content }\end{array}$ \\
\hline
\end{tabular}


Appendix (continued)

\begin{tabular}{|c|c|c|}
\hline Name & Location & Contribution \\
\hline $\begin{array}{l}\text { Chongshu Chen, } \\
\text { PhD }\end{array}$ & $\begin{array}{l}\text { Biogen, Cambridge, } \\
\text { MA }\end{array}$ & $\begin{array}{l}\text { Analyzed the data and } \\
\text { revised the manuscript for } \\
\text { intellectual content }\end{array}$ \\
\hline Sami Fam, PhD & $\begin{array}{l}\text { Biogen, Cambridge, } \\
\text { MA }\end{array}$ & $\begin{array}{l}\text { Designed and } \\
\text { conceptualized the } \\
\text { study; interpreted the } \\
\text { data; and revised the } \\
\text { manuscript for } \\
\text { intellectual content }\end{array}$ \\
\hline Fan Wu, PhD & $\begin{array}{l}\text { Biogen, Cambridge, } \\
\text { MA }\end{array}$ & $\begin{array}{l}\text { Analyzed the data and } \\
\text { revised the } \\
\text { manuscript for } \\
\text { intellectual content }\end{array}$ \\
\hline $\begin{array}{l}\text { Catherine Miller, } \\
\text { PharmD, MPH }\end{array}$ & $\begin{array}{l}\text { Biogen, Cambridge, } \\
\text { MA }\end{array}$ & $\begin{array}{l}\text { Designed and } \\
\text { conceptualized the } \\
\text { study; interpreted the } \\
\text { data; and revised the } \\
\text { manuscript for } \\
\text { intellectual content }\end{array}$ \\
\hline
\end{tabular}

\section{References}

1. Cohan SL, Moses H, Calkwood J, et al. Clinical outcomes in patients with relapsing remitting multiple sclerosis who switch from natalizumab to delayed-release dimethyl fumarate: a multicenter retrospective observational study (STRATEGY). Mult Scler Relat Disord 2018;22:27-34.

2. Fox RJ, Miller DH, Phillips JT, et al. Placebo-controlled phase 3 study of oral BG-12 or glatiramer in multiple sclerosis. N Engl J Med 2012;367:1087-1097.

3. Gold R, Arnold DL, Bar-Or A, et al. Long-term effects of delayed-release dimethy fumarate in multiple sclerosis: interim analysis of ENDORSE, a randomized extension study. Mult Scler 2017;23:253-265
4. Gold R, Kappos L, Arnold DL, et al. Placebo-controlled phase 3 study of oral BG-12 for relapsing multiple sclerosis. N Engl J Med 2012;367:1098-1107.

5. Fox RJ, Kita M, Cohan SL, et al. BG-12 (dimethyl fumarate): a review of mechanism of action, efficacy, and safety. Curr Med Res Opin 2014;30:251-262.

6. Kappos L, Gold R, Miller DH, et al. Efficacy and safety of oral fumarate in patients with relapsing-remitting multiple sclerosis: a multicentre, randomised, double-blind, placebo-controlled phase IIb study. Lancet 2008;372: 1463-1472.

7. Fox RJ, Chan A, Gold R, et al. Characterizing absolute lymphocyte count profiles in dimethyl fumarate-treated patients with MS: patient management considerations. Neurol Clin Pract 2016;6:220-229.

8. Mehta D, Miller C, Arnold DL, et al. Effect of dimethyl fumarate on lymphocytes in RRMS: implications for clinical practice. Neurology 2019; 92:e1724-e1738.

9. Fox RJ, Chan A, Gold R, et al. Characterization of absolute lymphocyte count profiles in MS patients treated with delayed-release dimethyl fumarate: considerations for patient management. Neurology 2016;86:P2.099.

10. Biogen Inc. Tecfidera ${ }^{\text {e }}$ (dimethyl fumarate) Delayed-Release Capsules, for Oral Use [online]. Available at: tecfidera.com/content/dam/commercial/multiple-sclerosis/ tecfidera/pat/en_us/pdf/full-prescribing-info.pdf. Accessed May 20, 2019.

11. European Medicines Agency. Tecfidera $120 \mathrm{mg}$ Gastro-Resistant Hard Capsules [online]. Available at: ema.europa.eu/documents/product-information/tecfideraepar-product-information_en.pdf. Accessed May 21, 2019.

12. Dammeier N, Schubert $\bar{V}$, Hauser TK, Bornemann A, Bischof F. Case report of a patient with progressive multifocal leukoencephalopathy under treatment with dimethyl fumarate. BMC Neurol 2015;15:108

13. Kappos L, Giovannoni G, Gold R, et al. Time course of clinical and neuroradiological effects of delayed-release dimethyl fumarate in multiple sclerosis. Eur J Neurol 2015; 22:664-671.

14. Sweetser MT, Dawson KT, Bozic C. Manufacturer's response to case reports of PML. N Engl J Med 2013;368:1659-1661.

15. Butzkueven $\mathrm{H}$, Chapman J, Cristiano E, et al. MSBase: an international, online registry and platform for collaborative outcomes research in multiple sclerosis. Mult Scler 2006;12:769-774

16. Briner M, Bagnoud M, Miclea A, et al. Time course of lymphocyte repopulation after dimethyl fumarate-induced grade 3 lymphopenia: contribution of patient age. Ther Adv Neurol Disord 2019;12:1756286419843450.

17. Zecca C, Antozzi CG, Torri Clerici V, et al, Severe multiple sclerosis reactivation during prolonged lymphopenia after dimethyl fumarate discontinuation. Acta Neurol Scand 2018;137:623-625.

18. Longbrake EE, Naismith RT, Parks BJ, Wu GF, Cross AH. Dimethyl fumarateassociated lymphopenia: risk factors and clinical significance. Mult Scler J Exp Trans Clin 2015;1:2055217315596994 


\section{Neurology ${ }^{\circ}$ Clinical Practice}

\section{Lymphocyte reconstitution after DMF discontinuation in clinical trial and real-world patients with MS}

Andrew Chan, John Rose, Enrique Alvarez, et al.

Neurol Clin Pract 2020;10;510-519 Published Online before print January 2, 2020

DOI 10.1212/CPJ.0000000000000800

This information is current as of January 2, 2020

$\begin{array}{ll}\begin{array}{l}\text { Updated Information \& } \\ \text { Services }\end{array} & \begin{array}{l}\text { including high resolution figures, can be found at: } \\ \text { http://cp.neurology.org/content/10/6/510.full.html }\end{array} \\ \text { References } & \text { This article cites } 16 \text { articles, } 1 \text { of which you can access for free at: } \\ & \text { http://cp.neurology.org/content/10/6/510.full.html\#\#ref-list-1 } \\ \text { Subspecialty Collections } & \text { This article, along with others on similar topics, appears in the } \\ & \text { following collection(s): } \\ & \text { All Clinical trials } \\ \text { http://cp.neurology.org//cgi/collection/all_clinical_trials } \\ \text { Multiple sclerosis } \\ \text { http://cp.neurology.org//cgi/collection/multiple_sclerosis } \\ \text { Information about reproducing this article in parts (figures,tables) or in } \\ \text { Permissions \& Licensing } & \text { its entirety can be found online at: } \\ & \text { http://cp.neurology.org/misc/about.xhtml\#permissions } \\ & \text { Information about ordering reprints can be found online: } \\ \text { http://cp.neurology.org/misc/addir.xhtml\#reprintsus }\end{array}$

Neurol Clin Pract is an official journal of the American Academy of Neurology. Published continuously since 2011, it is now a bimonthly with 6 issues per year. Copyright Copyright $\odot 2020$ The Author(s). Published by Wolters Kluwer Health, Inc. on behalf of the American Academy of Neurology.. All rights reserved. Print ISSN: 2163-0402. Online ISSN: 2163-0933.

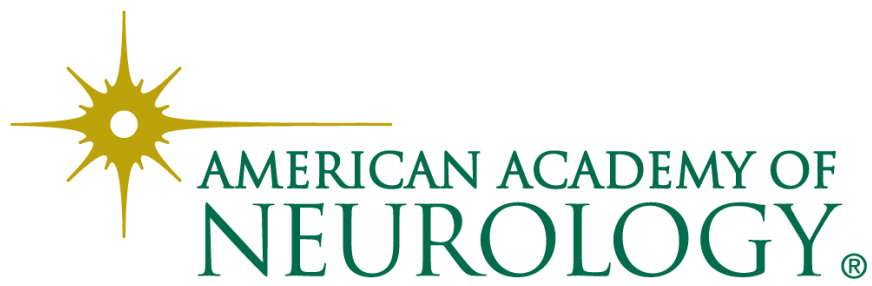

